\title{
Porphyrin-triarylamine conjugates: strong electronic communication between triarylamine redox centers via the porphyrin dication
}

\author{
Jung-Che Chang, ${ }^{a}$ Chi-Juan Ma, ${ }^{a}$ Gene-Hsiang Lee, ${ }^{b}$ Shie-Ming Peng ${ }^{b}$ and Chen-Yu Yeh ${ }^{* a}$ \\ a Department of Chemistry, National Chung Hsing University, Taiwan. \\ E-mail: cyyeh@dragon.nchu.edu.tw \\ ${ }^{b}$ Department of Chemistry, National Taiwan University, Taiwan
}

Received 15th November 2004, Accepted 11th March 2005

First published as an Advance Article on the web 21st March 2005

\begin{abstract}
A set of porphyrin-triarylamine hybrids have been synthesized in good yield by Sonogashira palladium-catalyzed cross-coupling reactions between the zinc complex of 5,15-diethynyl-10,20-dimesitylporphyrin and the appropriate iodophenyldiarylamines. The crystal structure of porphyrin 1 shows that the dihedral angle between the acetylene-bonded benzene rings and the porphyrin macrocycle is $20.0^{\circ}$. Such a structural characteristic enables effective electronic perturbations within the molecule. The electronic spectra are red-shifted and display a broad Soret band and an intense $\mathrm{Q}$ band relative to those of meso-substituted tetraarylporphyrins. These conjugates display four oxidations and one reduction. All the electrochemical reactions involve one-electron transfer. The first and second oxidations are reversible and can be assigned to the porphyrin-centered reactions. The third and fourth ones, separated by about $270 \mathrm{mV}$, correspond to the triarylamine units. The comproportionation constant $\left(K_{\mathrm{c}}\right)$ is calculated to be $3.67 \times 10^{4}$. The electron coupling between the triarylamine moieties, at a separation of $>23 \AA$, is remarkably strong. The electrochemical results and the absorption spectra show that the electronic characteristics of these porphyrins can be significantly modulated by the triarylamine substituents via the conjugated carbon-carbon triple bond. Variations of the substituents on the triarylamines can fine-tune the electronic properties of these molecules.
\end{abstract}

\section{Introduction}

The preparation of new materials for molecular electronics and photonic devices is a rapidly developing field in recent years. ${ }^{1}$ Porphyrins are an appealing class of macromolecules due to their unique photophysical and electrochemical properties. ${ }^{2}$ Because the porphyrin framework is a rigid unit and has twelve sites for functionalization, it is possible to precisely control the properties of porphyrins by fine tuning the peripheral substituents. In meso-substituted tetraarylporphyrins, the electronic perturbation is only moderate since the aryl groups twist out of the porphyrin ring leading to interruption of the $\pi$-conjugation..$^{3-5}$ Aromatic ring fusion on the pyrrolic subunits has been systematically investigated. ${ }^{6,7}$ In some cases such as naphthyleneand acenaphtylene-fused porphyrins, significant red shifts of the UV-Vis absorptions have been noted. To increase the electronic interaction between the substituents and the porphyrin ring, numerous examples of porphyrins with aryl groups linked via ethyne, ethylene, imine and azo bridges have been studied. ${ }^{8-10}$ The azo and ethyne bridges exhibit better conjugation than the imine and ethylene links because the imine- and ethylene-linked porphyrins show twists across the bridging unit, resulting in reduced conjugation. In the multiporphyrin system, a variety of linkages such as ethyne, polyyne, ethylene, alkyl and aromatic entities have been used to bridge the chromophores. ${ }^{11-19}$ It has been shown that acetylenic substituents are ideal linkers to enable strong interporphyrin electronic communication. ${ }^{10,11,20-22}$

Recently, numerous efforts have been devoted to the synthesis and studies of triarylamines because of their wide utility in hole transporting materials, dyes and polymers. ${ }^{23,24}$ Since triarylamine can be reversibly oxidized, and the intervalence charge-transfer bands are relatively intense and are separated from other bands, they have been used for studies of electron transfer reactions which are one of the fundamental processes in biology and chemistry. ${ }^{25-29}$ Although a wide variety of bridges such as aromatic rings and unsaturated carbon-carbon bonds have been used to link two triarylamine moieties, examples showing electronic coupling between the triarylamine units through a porphyrin $\pi$ system have not yet been reported. In this paper, we describe the synthesis, structure and electrochemical properties of a series of triarylamine-porphyrin conjugates. The triarylamine moieties display unprecedented strong coupling via the diethynylporphyrin unit and the ethyne bridge provides enhanced electronic interaction between the porphyrin ring and the triarylamine substituents.

\section{Results and discussion}

\section{Synthetic design}

Several conjugated molecules comprised of two redox active groups and a porphyrin spacer have been synthesized. ${ }^{30-33}$ A key requirement for the spacer to be considered as a potential molecular wire is strong coupling between the redox active units. ${ }^{34,35}$ However, examples showing coupling between the two redox active sites are rare. ${ }^{31}$ We have designed a new class of triarylamine-porphyrin conjugates in which the porphyrin and triarylamine subunits are linked by a carboncarbon triple bond (Scheme 1). This structural characteristic provides an extensive conjugation over the whole molecule and may result in strong coupling between the triarylamine units. The synthesis of compounds 1-3 relies on Sonogashira crosscoupling reactions and is based on the key building blocks, porphyrin $\mathbf{5}^{36}$ and the corresponding iodides (Scheme 1). ${ }^{35}$ For comparison, the zinc complex of 5,15-bis(phenylethynyl)-10,20dimesitylporphyrin (4) was also synthesized. The $N, N$-diaryl- $N$ (4-iodophenyl)amines were synthesized by amination of aniline with the corresponding aryl iodide, followed by iodination. The general cross-coupling conditions for the synthesis of porphyrin-triarylamine conjugates under various conditions using $\mathrm{Pd}\left(\mathrm{PPh}_{3}\right)_{4}$ or $\mathrm{Pd}(\mathrm{OAc})_{2}$ catalyst, $\mathrm{CuI}$ cocatalyst, and an alkyl amine as a base in THF or toluene led to a totally insoluble porphyrin solid formed by homocoupling of porphyrin 5. The desired product was isolated in a yield less than $5 \%$. When the coupling reaction was performed in pyrrolidine using $\mathrm{Pd}\left(\mathrm{PPh}_{3}\right)_{4}$ as the catalyst and $\mathrm{CuI}$ as the cocatalyst, the expected product was obtained in good yield without the formation of 


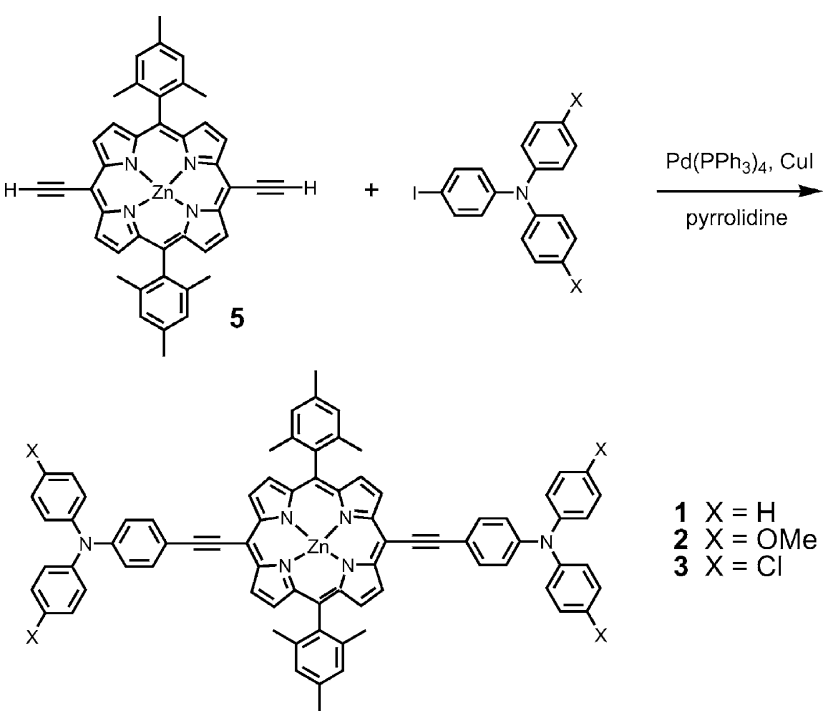

Scheme 1

the insoluble porphyrin solid. All the new compounds were well characterized by various spectroscopic methods.

\section{Crystal structure}

Crystals of 1 were grown from slow diffusion of methanol into the solution of $\mathbf{1}$ in a mixture of THF and pyridine. Fig. 1 shows the ORTEP diagram of compound $\mathbf{1}$. The structural analysis reveals that the metal center is four coordinate. The bond distances and angles in the porphyrin core are similar to those observed in the 5,10,15,20-tetraarylporphyrin system. ${ }^{37,38}$ The porphyrin framework is nearly planar, as indicated by the fact that the root-mean-square deviation of fitted atoms is $0.03 \AA$. The acetylene groups essentially lie within the mean plane of the porphyrin. The mesityl groups and the porphyrin plane are nearly orthogonal with a dihedral angle of $83.57^{\circ}$. Strong electronic interaction requires efficient $\pi$-orbital overlap and this can be examined by the dihedral angles between the aromatic rings. The dihedral angle between the acetylene-bonded benzene rings and the porphyrin macrocycle is $20.0^{\circ}$, which is larger by $3.4^{\circ}$ than that in 5,15-bis[(4'-methoxyphenyl)ethynyl]-10,20diphenylporphyrin. ${ }^{10}$ Previous reports using molecular mechanics calculations showed that there is no barrier to rotation for the aromatic rings attached to the acetylene bridge in the meso arylethynyl-substituted porphyrins. ${ }^{9,39}$ The deviation from a coplanar arrangement in compound $\mathbf{1}$ may result from the crystal packing interactions. ${ }^{10,39}$ The carbon-carbon triple bonds $(\mathrm{C}(20)-\mathrm{C}(21))$ are unexceptional with a bond length of $1.203 \AA$, and the respective bond distances of $\mathrm{C}(21)-\mathrm{C}(22)$ and $\mathrm{C}(10)$ $\mathrm{C}(20)$ are 1.437 and $1.436 \AA$, indicating that there is no cumulenic character in this compound. The $-\mathrm{C} \equiv \mathrm{C}$ - chain slightly deviates from linearity, with bond angles at $\mathrm{C}(20)$ and $\mathrm{C}(21)$ of 177.53 and $173.74^{\circ}$, respectively. In the triarylamine units, the dihedral angles between the benzene rings and the plane defined by $\mathrm{N}$-bonded carbon atoms $(\mathrm{C}(25), \mathrm{C}(28)$ and $\mathrm{C}(34))$ are in the range from 31.64 to $46.88^{\circ}$, which are comparable to those of triphenylamine. ${ }^{40}$

\section{Electronic absorption}

The electronic interaction between the triarylamine and porphyrin macrocycle can be investigated by UV-Vis absorption spectra, for example, the peak broadening, peak shifts and changes in the oscillator strength of absorptions. ${ }^{10,38}$ The absorption spectra of these conjugates are very different from the sum of their respective components: porphyrin $\mathbf{5}$ and the corresponding triarylamines. As an example, Fig. 2 shows the UV-Vis spectra

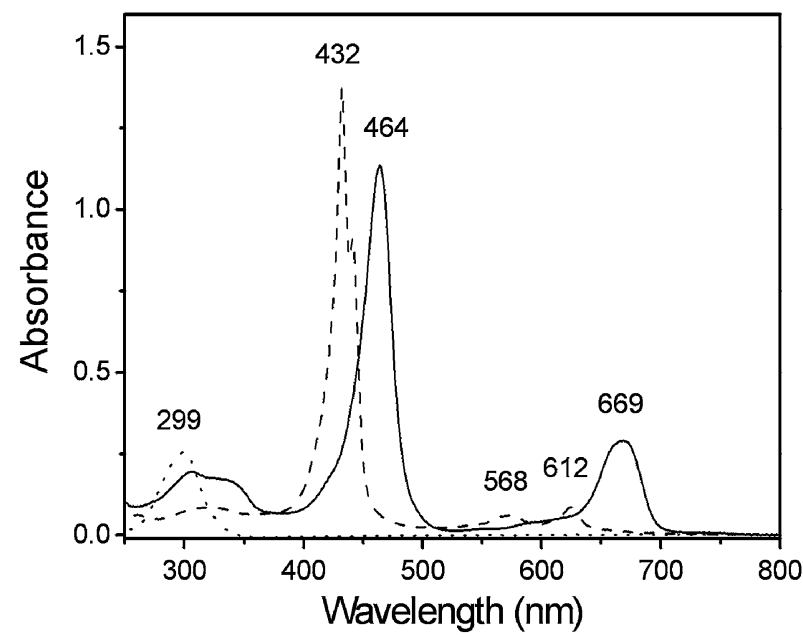

Fig. 2 UV-Vis spectra of $\mathbf{1}\left(-\right.$, conc. $\left.=4.84 \times 10^{-6} \mathrm{M}\right), \mathbf{5}(---$, conc. $=$ $\left.4.84 \times 10^{-6} \mathrm{M}\right)$, and triphenylamine $\left(\cdots\right.$, conc. $\left.=9.68 \times 10^{-6} \mathrm{M}\right)$ in THF.

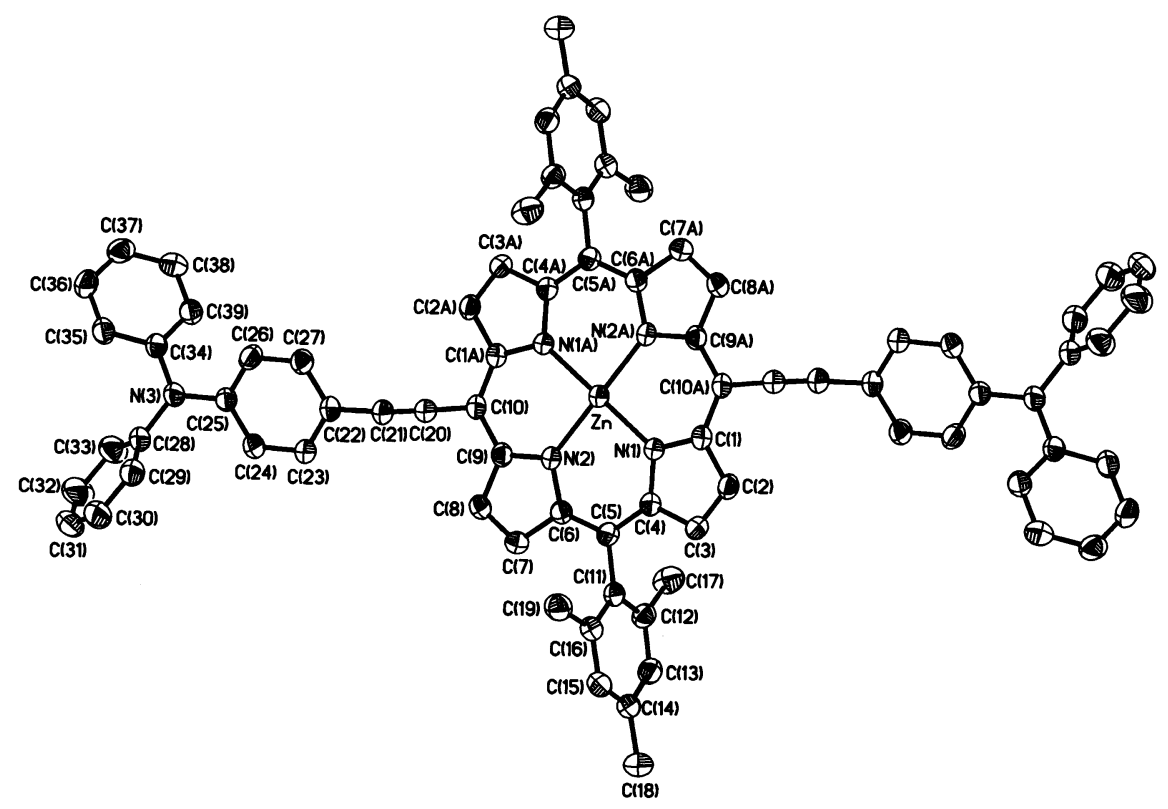

Fig. 1 ORTEP drawing of compound 1 (50\% probability thermal ellipsoids). Hydrogen atoms and the pyridine molecule are omitted for clarity. 
Table 1 Summary of electronic spectra for compounds 1-4

\begin{tabular}{ccccc}
\hline & FWHM $^{a}$, B-band $/ \mathrm{cm}^{-1}(\mathrm{~nm})$ & $f_{\mathrm{B}}{ }^{b}$ & FWHM, Q-band/cm ${ }^{-1}(\mathrm{~nm})$ \\
\hline $\mathbf{1}$ & $1346(464)$ & 1.45 & $893(669)$ & 0.24 \\
$\mathbf{2}$ & $1918(468)$ & 1.40 & $1002(679)$ & 0.26 \\
$\mathbf{3}$ & $1278(469)$ & 1.43 & $856(677)$ & 0.22 \\
$\mathbf{4}$ & $740(447)$ & 1.51 & $601(651)$ & 0.18
\end{tabular}

${ }^{a}$ Spectral width of the B band at half the height of $\lambda_{\max } \cdot{ }^{b}$ Oscillator strengths calculated over the region from 360 to 550 nm. ${ }^{c}$ Oscillator strengths calculated over the region from 550 to $750 \mathrm{~nm}$.

of compounds $\mathbf{1}$ and $\mathbf{5}$, and triphenylamine. The attachment of triphenylamine units to the porphyrin via the carbon-carbon triple bond leads to significant perturbation of the groundstate properties of the porphyrin ring. The electronic absorption data for porphyrins 1-4 are summarized in Table 1. In the porphyrin-triarylamine conjugates both the Soret and Q bands show a large red shift, indicating a decreased energy gap between the HOMO and LUMO orbitals as a consequence of the expanded $\pi$-conjugation. ${ }^{10,39}$ Furthermore, these compounds exhibit a broadening of the Soret band. This again reveals the strong conjugation between the porphyrin and the triarylamines. It should be noted that compounds 1-3 exhibit significantly enhanced oscillator strength of the $\mathrm{Q}$ band. This can be explained by the enhanced energy splitting between the $\mathrm{a}_{1 \mathrm{u}}$ and $\mathrm{a}_{2 \mathrm{u}}$ orbitals, or the $\mathrm{E}_{\mathrm{g}}$ orbitals. ${ }^{10,41}$

\section{Electrochemistry}

It is well known that zinc porphyrins can undergo two oxidations and two reductions while the triarylamine system is reversibly oxidizable. The nature of the substituents on the terminal phenyls would be reflected by the redox potentials of these dyads. It is expected that stepwise one-election oxidations for the two triarylamine units can be observed due to electronic communication. The electrochemistry of these compounds was examined by cyclic voltammetry. As an example, Fig. 3 shows the anodic cyclic voltammograms for compound $\mathbf{1}$ in benzonitrile. All the electrochemical reactions involve one-electron transfer judging from the magnitude of the waves. Since arylamines are electron-donating groups, the first two oxidation reactions corresponding to the porphyrin ring center at potentials of $E_{1 / 2}(\mathrm{ox} 1)=+0.74$ and $E_{1 / 2}(\mathrm{ox} 2)=+0.98 \mathrm{~V}$, are significantly shifted as compared to those of compound 4 (Table 2). The triarylamine centers show two more or less reversible oxidations at potentials of $E_{1 / 2}(\mathrm{ox} 3)=+1.23$ and $E_{1 / 2}(\mathrm{ox} 4)=+1.50$. From the separation of the redox potentials, a comproportionation constant $\left(K_{\mathrm{c}}\right)$ of $3.67 \times 10^{4}$ is obtained, ${ }^{42}$ indicative of strong coupling between the redox centers. It should be noted that

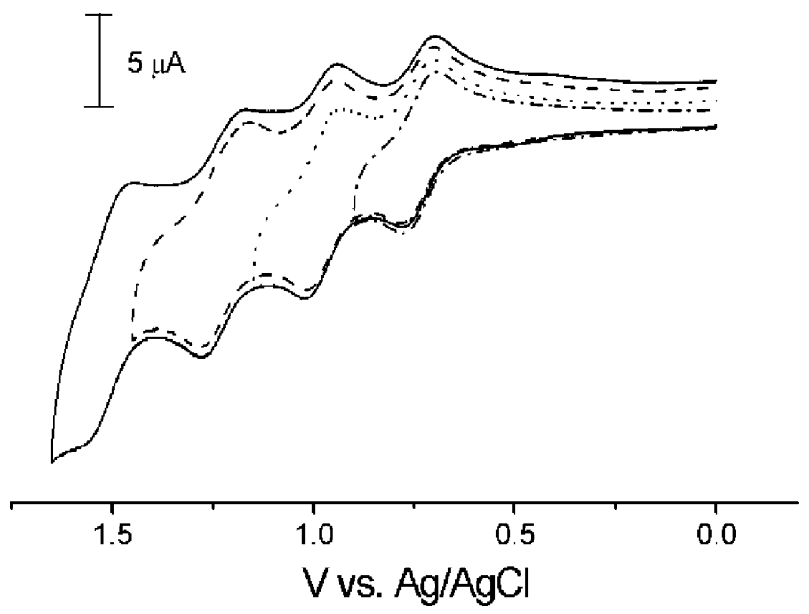

Fig. 3 Cyclic voltammograms of compound 1 in benzonitrile $(0.1 \mathrm{M}$ TBAP).
Table 2 Electrochemical data for compounds $\mathbf{1}-\mathbf{4}^{a}$

\begin{tabular}{llllll}
\hline & $E_{1 / 2}(\mathrm{ox} 1)$ & $E_{1 / 2}(\mathrm{ox} 2)$ & $E_{1 / 2}(\mathrm{ox} 3)$ & $E_{1 / 2}(\mathrm{ox} 4)$ & $E_{1 / 2}(\mathrm{red} 1)$ \\
\hline $\mathbf{1}$ & 0.74 & 0.98 & $1.23^{b}$ & $1.50^{b}$ & -1.07 \\
$\mathbf{2}$ & 0.67 & 0.83 & $0.99^{b}$ & $1.32^{b}$ & -1.06 \\
$\mathbf{3}$ & 0.77 & 1.03 & $1.28^{b}$ & $1.50^{c}$ & -1.05 \\
$\mathbf{4}$ & 0.87 & 1.26 & & & -1.01
\end{tabular}

${ }^{a}$ Potentials (V) are reported vs. $\mathrm{Ag} / \mathrm{AgCl}$ (saturated) and referenced to the ferrocene-ferrocenium $\left(\mathrm{Fc} / \mathrm{Fc}^{+}\right)$couple which occurs at $E_{1 / 2}=$ $+0.54 \mathrm{~V}$ vs. $\mathrm{Ag} / \mathrm{AgCl}$ (saturated). The anodic and cathodic redox data are obtained in benzonitrile and THF, respectively. ${ }^{b}$ Quasi-reversible reaction. ${ }^{c}$ Irreversible reaction.

the coupling between the triarylamine units is not through the neutral diethynyl $\mathrm{Zn}$ (II) porphyrin but through its dicationic form because the porphyrin ring is oxidized prior to the triarylamines.

Lambert and Nöll systematically studied the redox properties and the electronic coupling of a series of $\pi$-conjugated bistriarylamine compounds with varying $\mathrm{N} \cdots \mathrm{N}$ distances from 5.6 to $19.3 \AA$. The redox potential splitting $\left(E_{1 / 2}(\right.$ ox 2$)-E_{1 / 2}($ ox 1$\left.)\right)$ of the triarylamine units ranges from 60 to $485 \mathrm{mV}^{26}$ In our system, the triarylamine centers, with an $\mathrm{N} \cdots \mathrm{N}$ separation of $>23 \AA$. display a strong electronic coupling, indicating that the porphyrin is an efficient bridge for mediating the electronic interaction between triarylamine units.

A number of reports have presented the redox properties of porphyrin systems linked to other redox active moieties such as fullerenes, quinones, viologens and ferrocenes. ${ }^{43-46}$ In a few examples of ferrocenylporphyrin dyads, ${ }^{30,31}$ the porphyrin macrocycle is used as a linker to study its efficiency for mediating electronic coupling between the ferrocenyl units. In the system of 5,15-diferrocenylethynyl-10,20-diphenylporphyrin, the ferrocenyl moieties with an estimated separation of $<20 \AA$ behave independently. ${ }^{30}$ One of the key requirements for efficient electronic communication is good overlap between the orbitals of the bridging unit and the redox centers on the ends. ${ }^{41}$ Thus, the significant differences between these two porphyrintriarylamine and porphyrin-ferrocene systems indicate that the frontier orbitals of triarylamine units can overlap and match in energy with those of the porphyrin dication $\mathbf{1}^{2+}$, which results in effective electronic communication.

The electrochemical reactions of our compounds were also studied by spectroelectrochemistry. Fig. 4 shows the spectral changes of compound $\mathbf{2}$ at various applied potentials. Upon one- and two-electron oxidation, a broad band in the NIR region is observed, which is absent in simple porphyrins such as 5,10,15,20-tetraphenylporphyrin and 5,10,15,20tetramesitylporphyrin. This broad band can be ascribed to the charge transfer between the triarylamine units and the porphyrin cation/dication. Further oxidation at a potential of $+1.15 \mathrm{~V}$ leads to decomposition of the complex. Thus, evaluation of the coupling energy $V$ between the triarylamine centers was unsuccessful.

Substituent effects on porphyrin redox properties have been extensively studied. ${ }^{47-52}$ The magnitude of substituent effects depends on a number of parameters such as the number, nature 


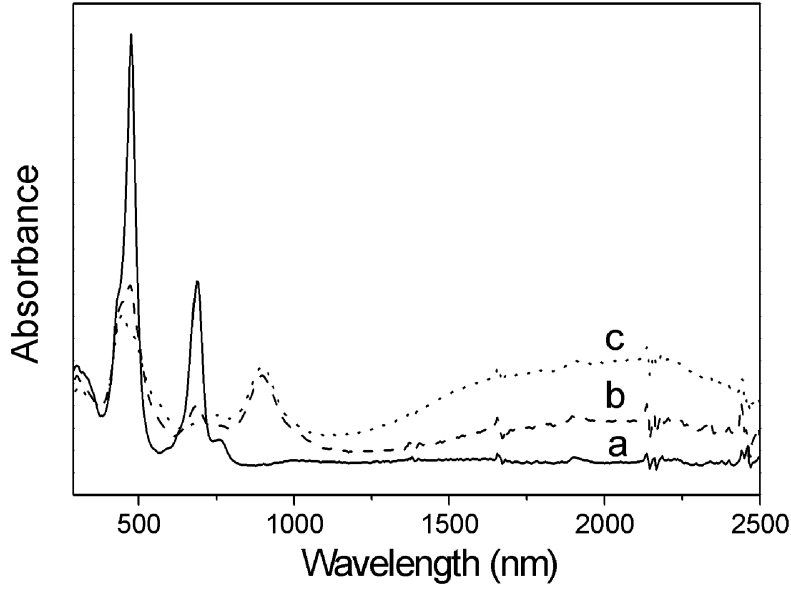

Fig. 4 Spectral changes of compound 2 in benzonitrile (0.1 M TBAP) at applied potentials of (a) $+0.30,(\mathrm{~b})+0.75$ and $(\mathrm{c})+0.90 \mathrm{~V}$.

and location of substituents. Generally, attachment of electronreleasing groups to the porphyrin core facilitates oxidation and retards reduction of the porphyrin ring. In contrast, the addition of electron-withdrawing groups to the macrocycle shifts both the oxidation and reduction to a positive direction. For example, Kadish and co-workers investigated substituent effects on the electrochemical properties of $\mathrm{Zn}\left(\mathrm{TPPBr}_{x}\right)$ where $\mathrm{TPPBr}_{x}$ is the dianion of $\beta$-brominated 5,10,15,20-tetraphenylporphyrin, $x=$ $0-8 .{ }^{47}$ The redox potentials for the first oxidation only extended by $160 \mathrm{mV}$ from $\mathrm{Zn}(\mathrm{TPP})$ to $\mathrm{Zn}\left(\mathrm{TPPBr}_{8}\right)$. In our system, the $\mathrm{ZnP}^{+} / \mathrm{ZnP}$ and $\mathrm{ZnP}^{2+} / \mathrm{ZnP}^{+}$redox potentials span over a 100 and $200 \mathrm{mV}$ range, respectively (Table 2 ). The substituent effects on the redox potentials of the porphyrin ring are remarkable when considering the remote distances from the substituents to the porphyrin macrocycle.

\section{Conclusions}

In conclusion, we report the first examples of porphyrintriarylamine conjugates in which the triarylamine redox centers are positioned at a fixed distance by a porphyrin linker with a well-defined geometry. Red shifts and peak broadening of the absorption spectra are indicative of electronic coupling between the chromophores. Electrochemical data show that there is strong electronic communication between the two remote redox centers with a separation of $>2 \mathrm{~nm}$. This finding suggests that this new class of conjugates has the potential for application in "molecular wires" and related devices. To evaluate the coupling energy $V$, it is required to synthesize a more stable system that allows us to analyze the intervalence charge transfer absorptions upon oxidation of the triarylamine units. Work along these lines is in progress in our laboratory.

\section{Experimental}

All reagents and solvents were obtained from commercial sources and were used without further purification unless otherwise noted. Benzonitrile used for electrochemistry was dried over $\mathrm{CaH}_{2}$ and freshly distilled prior to use. Tetra- $n$ butylammonium perchlorate (TBAP) was recrystallized twice from ethyl acetate and further dried under vacuum. Absorption spectra were recorded on a Perkin Elmer Lambda 900 series spectrophotometer. ESI-MS mass spectra were obtained with a Finnigan MAT LCQ spectrometer operating in the positive ion detection mode. Electrochemistry was performed with a three-electrode potentiostat ( $\mathrm{CH}$ Instruments, Model 750A) in benzonitrile or THF which were deoxygenated by purging with prepurified nitrogen gas. Cyclic voltammetry was conducted with the use of a home-made three-electrode cell equipped with a BAS glassy carbon $\left(0.07 \mathrm{~cm}^{2}\right)$ or platinum $\left(0.02 \mathrm{~cm}^{2}\right)$ disk as the working electrode, a platinum wire as the auxiliary electrode, and a home-made $\mathrm{Ag} / \mathrm{AgCl}$ (saturated) reference electrode. The reference electrode is separated from the bulk solution by a double junction filled with electrolyte solution. Potentials are reported $v s . \mathrm{Ag} / \mathrm{AgCl}$ (saturated) and referenced to the ferrocene-ferrocenium $\left(\mathrm{Fc} / \mathrm{Fc}^{+}\right)$couple which occurs at $E_{1 / 2}=+0.54 \mathrm{~V} v s . \mathrm{Ag} / \mathrm{AgCl}$ (saturated). The working electrode was polished with $0.03 \mu \mathrm{m}$ aluminium on Buehler felt pads and was subjected to ultrasound for $1 \mathrm{~min}$ prior to each experiment. The reproducibility of individual potential values was within \pm 5 $\mathrm{mV}$. The spectroelectrochemical experiments were accomplished with the use of a $1 \mathrm{~mm}$ cuvette, a 100 mesh platinum gauze as working electrode, a platinum wire as auxiliary electrode, and a $\mathrm{Ag} / \mathrm{AgCl}$ (saturated) reference electrode.

\section{(5,15-Bis $(4-(N, N$-diphenylamino)phenylethynyl)-10,20- dimesitylporphyrinato)zinc(II) (1)}

A mixture of $N, N$-diphenyl- $N$-(4-iodophenyl)amine $(23 \mathrm{mg}$, $0.062 \mathrm{mmol})$ and porphyrin $5(20 \mathrm{mg}, 0.030 \mathrm{mmol})$ in dry pyrrolidine $(15 \mathrm{~mL})$ was degassed with nitrogen for $10 \mathrm{~min}$. Then $\mathrm{Pd}\left(\mathrm{PPh}_{3}\right)_{4}(7 \mathrm{mg}, 0.006 \mathrm{mmol})$ and $\mathrm{CuI}(1 \mathrm{mg}, 0.006 \mathrm{mmol})$ were added. The solution was further degassed for another $10 \mathrm{~min}$. Before the solvent was evaporated to dryness in vacuum, the reaction mixture was stirred for $1 \mathrm{~h}$ at room temperature. The product was purified by column chromatography on silica gel using $\mathrm{CH}_{2} \mathrm{Cl}_{2}$-hexanes $(1: 1)$ as the eluent. Solvent was removed under reduced pressure to give a pure dark green solid $(24 \mathrm{mg}$, $70 \%) .{ }^{1} \mathrm{H} \mathrm{NMR}\left(\mathrm{CDCl}_{3}\right): \delta 9.65(\mathrm{~d}, J=4.4 \mathrm{~Hz}, 4 \mathrm{H}), 8.70(\mathrm{~d}, J=$ $4.4 \mathrm{~Hz}, 4 \mathrm{H}), 7.82(\mathrm{~d}, J=8.0 \mathrm{~Hz}, 4 \mathrm{H}), 7.15-7.4(\mathrm{~m}, 24 \mathrm{H}), 7.11$ $(\mathrm{t}, J=8.0 \mathrm{~Hz}, 4 \mathrm{H}), 2.63(\mathrm{~s}, 6 \mathrm{H}), 1.83(\mathrm{~s}, 12 \mathrm{H}) ; \mathrm{UV} / \mathrm{Vis}(\mathrm{THF})$ $\lambda_{\max } / \mathrm{nm}(\log \varepsilon): 464$ (5.37), 669 (4.79); MS (ESI): $m / z 1142\left(\mathrm{M}^{+}\right)$. $\mathrm{C}_{78} \mathrm{H}_{58} \mathrm{~N}_{6} \mathrm{Zn}$ : Calc.: C 81.84, H 5.11, N 7.34. Found: C 81.58, H $5.22, \mathrm{~N} 7.13 \%$

\section{(5,15-Bis(4-( $N, N$-bis(4-methoxyphenyl)amino)phenylethynyl)-} 10,20-dimesitylporphyrinato)zinc(II) (2)

This compound was prepared from $\mathbf{5}$ and $N, N$-bis(4methoxyphenyl)- $N$-(4-iodophenyl)amine by employing a procedure similar to that for compound 1 (yield: $71 \%$ ). ${ }^{1} \mathrm{H}$ NMR $\left(\mathrm{CDCl}_{3}\right): \delta 9.64(\mathrm{~d}, J=4.4 \mathrm{~Hz}, 4 \mathrm{H}), 8.69(\mathrm{~d}, J=4.4 \mathrm{~Hz}, 4 \mathrm{H}), 7.75$ $(\mathrm{d}, J=8.4 \mathrm{~Hz}, 4 \mathrm{H}), 7.27(\mathrm{~s}, 4 \mathrm{H}), 7.15(\mathrm{~d}, J=8.4 \mathrm{~Hz}, 8 \mathrm{H}), 7.02$ $(\mathrm{d}, J=8.4 \mathrm{~Hz}, 4 \mathrm{H}), 6.87(\mathrm{~d}, J=8.4 \mathrm{~Hz}, 8 \mathrm{H}), 3.80(\mathrm{~s}, 12 \mathrm{H}), 2.62$ (s, 6H), 1.82 (s, 12H); UV/Vis (THF): $\lambda_{\max } / \mathrm{nm}(\log \varepsilon): 468$ (5.21), 678 (4.76); MS (ESI): $m / z 1262\left(\mathrm{M}^{+}\right) . \mathrm{C}_{82} \mathrm{H}_{66} \mathrm{~N}_{6} \mathrm{O}_{4} \mathrm{Zn}$ : Calc.: $\mathrm{C}$ 77.87, H 5.26, N 6.64. Found: C 78.03, H 5.33, N 6.52\%.

\section{(5,15-Bis(4-( $N, N$-bis(4-chlorophenyl)amino)phenylethynyl)- 10,20-dimesitylporphyrinato)zinc(II) (3)}

This compound was prepared from 5 and $N, N$-bis(4chlorophenyl)- $N$-(4-iodophenyl)amine by employing a procedure similar to that for compound 1 (yield: $65 \%$ ). ${ }^{1} \mathrm{H}$ NMR ([D $\left.\left.\mathrm{D}_{6}\right] \mathrm{DMSO}\right): \delta 9.57$ (d, $\left.J=4.4 \mathrm{~Hz}, 4 \mathrm{H}\right), 8.53(\mathrm{~d}, J=4.4 \mathrm{~Hz}$, $4 \mathrm{H}), 7.97(\mathrm{~d}, J=8.4 \mathrm{~Hz}, 4 \mathrm{H}), 7.44(\mathrm{~d}, J=8.4 \mathrm{~Hz}, 8 \mathrm{H}), 7.34$ (s, 4H), 7.15-7.20 (m, 12H), $3.80(\mathrm{~s}, 12 \mathrm{H}), 2.60(\mathrm{~s}, 6 \mathrm{H}), 1.80(\mathrm{~s}$, $12 \mathrm{H})$; UV/Vis (THF): $\lambda_{\max } / \mathrm{nm}(\log \varepsilon)=461$ (5.40), 677 (4.75); MS (ESI): $m / z 1282\left(\mathrm{M}^{+}\right) . \mathrm{C}_{78} \mathrm{H}_{54} \mathrm{Cl}_{4} \mathrm{~N}_{6} \mathrm{Zn}$ : Calc.: $\mathrm{C} 73.05, \mathrm{H}$ 4.24, N 6.55. Found: C 73.18, H 4.17, N 6.62\%.

\section{(5,15-Bis(phenylethynyl)-10,20-dimesitylporphyrinato)- zinc(II) (4)}

This compound was prepared from $\mathbf{5}$ and iodobenzene by employing a procedure similar to that for compound $\mathbf{1}$ (yield: $68 \%) .{ }^{1} \mathrm{H} \mathrm{NMR}\left(\mathrm{CDCl}_{3}\right): \delta 9.70(\mathrm{~d}, J=4.4 \mathrm{~Hz}, 4 \mathrm{H}), 8.75(\mathrm{~d}, J=$ $4.4 \mathrm{~Hz}, 4 \mathrm{H}), 8.00(\mathrm{~d}, J=8.4 \mathrm{~Hz}, 4 \mathrm{H}), 7.40-7.60(\mathrm{~m}, 6 \mathrm{H}), 7.29(\mathrm{~s}$, $4 \mathrm{H}), 2.64(\mathrm{~s}, 6 \mathrm{H}), 1.83(\mathrm{~s}, 12 \mathrm{H}) ; \mathrm{UV} / \mathrm{Vis}(\mathrm{THF}) \lambda_{\max } / \mathrm{nm}(\log \varepsilon)$ : 447 (5.64), 651 (4.74); MS (ESI): $m / z 809\left(\mathrm{M}^{+}\right) . \mathrm{C}_{54} \mathrm{H}_{40} \mathrm{~N}_{4} \mathrm{Zn}$ : Calc.: C 80.04, H 4.98, N 6.91. Found: C 79.89, H 5.06, N $6.78 \%$. 


\section{X-Ray crystallographic study}

Crystals were grown from slow diffusion of methanol in a solution of $\mathbf{1}$ in a mixture of THF and pyridine. Crystal data for $1 \cdot \mathrm{C}_{5} \mathrm{H}_{5} \mathrm{~N}: M_{\mathrm{r}}=1223.77$, triclinic, space group $P \overline{1}, T=$ $150(2) \mathrm{K}, a=7.0958(4), b=14.3751(8), c=15.7008(10) \AA, a=$ 102.799(3), $\beta=93.972(4), \gamma=94.086(4)^{\circ}, V=1551.80(16)$ $\AA^{3}, Z=1, \mu=0.451 \mathrm{~mm}^{-1}, D_{\mathrm{c}}=1.310 \mathrm{~g} \mathrm{~cm}^{-3} .15547$ reflections collected, 5456 independent, $R_{\text {int }}=0.0553$, final residuals $R 1=0.0503, w R 2=0.1226[I>2 \sigma(I)] ; R 1=0.0768$, $w R 2=0.1396$ (all data). The chosen crystal was mounted on a glass fiber. Data collection was carried out on a NONIUS KappaCCD diffractometer with Mo radiation $(\lambda=0.71073 \AA)$. Cell parameters were retrieved and refined using DENZOSMN software on all observed reflections. ${ }^{53}$ Data reduction was performed with the DENZO-SMN software. ${ }^{53}$ An empirical absorption was based on the symmetry-equivalent reflections and absorption corrections were applied with the SORTAV program. ${ }^{54}$ All the structures were solved by using the SHELXS$97^{55}$ and refined with SHELXL-97 $7^{56}$ by full-matrix least squares on $F^{2}$ values. Hydrogen atoms were fixed at calculated positions and refined using a riding mode.

CCDC reference number 251070.

See http://www.rsc.org/suppdata/dt/b4/b417350c/ for crystallographic data in CIF or other electronic format.

\section{Acknowledgements}

We thank the National Science Council of Taiwan for financial support. We also thank Professor Ru-Jen Cheng for helpful discussions and Professor Kuan-Jiuh Lin for the access of UVVis-NIR spectrometer.

\section{References}

1 J. M. Tour, Molecular Electronics: Commercial Insights, Chemistry, Devices, Architecture and Programming, World Scientific, London, 2003.

2 K. M. Kadish, K. M. Smith and R. Guilard, The Porphyrin Handbook, Academic Press, London, 2000, vol. 8.

3 J. B. Kim, J. J. Leonard and F. R. Longo, J. Am. Chem. Soc., 1972, 94, 3986-3992.

4 D. J. Zuimby and F. R. Longo, J. Am. Chem. Soc., 1975, 97, 51115117.

5 P. J. Spellane, M. Gouterman, A. Antipas, S. Kim and Y. C. Liu, Inorg. Chem., 1980, 19, 386-391.

6 J. D. Spence and T. D. Lash, J. Org. Chem., 2000, 65, 1530-1539.

7 T. D. Lash, T. M. Werner, M. L. Thompson and J. M. Manley, J. Org. Chem., 2001, 66, 3152-3159.

8 T. E. O. Screen, I. M. Blake, L. H. Rees, W. Clegg, S. J. Borwick and H. L. Anderson, J. Chem. Soc., Perkin Trans. 1, 2002, 320-329.

9 H. L. Anderson, A. P. Wylie and K. Prout, J. Chem. Soc., Perkin Trans. 1, 1998, 1607-1611.

10 S. M. LeCours, S. G. DiMagno and M. J. Therien, J. Am. Chem. Soc., 1996, 118, 11854-11864.

11 V. S.-Y. Lin, S. G. DiMagno and M. J. Therien, Science, 1994, 264, 1105-1111.

12 T. V. Duncan, I. V. Rubtsov, H. T. Uyeda and M. J. Therien, J. Am. Chem. Soc., 2004, 126, 9474-9475.

13 N. P. Redmore, I. V. Rubtsov and M. J. Therien, J. Am. Chem. Soc., 2003, 125, 8769-8778.

14 H. L. Anderson, S. J. Martin and D. D. C. Bradley, Angew. Chem., Int. Ed. Engl., 1994, 33, 655-657.

15 D. P. Arnold, R. D. Hartnell, G. A. Heath, L. Newby and R. D. Webster, Chem. Commun., 2002, 754-755.

16 R. W. Wagner and J. S. Lindsey, J. Am. Chem. Soc., 1994, 116, 97599760 .

17 H. Kamogawa, S. Miyama and S. Minoura, Macrocycles, 1989, 22, 2123-2126.
18 J. L. Sessler, J. Hugdall and M. R. Johnson, J. Org. Chem., 1986, 51, 2838-2840.

19 C. K. Chang and I. Abdalmuhdi, J. Org. Chem., 1983, 48, 5388-5390.

20 D. P. Arnold, G. A. Heath and D. A. James, J. Porphyrins Phthalocyanines, 1999, 3, 5-31.

21 J. Wytko, V. Berl, M. McLaughlin, R. R. Tykwinski, M. Schreiber and F. Diederich, Helv. Chim. Acta, 1998, 81, 1964-1977.

22 K. Susumu, H. Maruyama, H. Kobayashi and K. Tanaka, J. Mater. Chem., 2001, 11, 2262-2270.

23 T. D. Selby and S. C. Blackstock, J. Am. Chem. Soc., 1998, 120, 12155-12156.

24 C.-T. Chen, C.-L. Chiang, Y.-C. Lin, L.-H. Chan, C.-H. Huang, Z.W. Tsai and C.-T. Chen, Org. Lett., 2003, 5, 1261-1264.

25 C. Lambert and G. Nöll, Synth. Met., 2003, 57-62.

26 C. Lambert and G. Nöll, J. Am. Chem. Soc., 1999, 121, 8434-8442.

27 M. M. Wienk and R. A. J. Janssen, J. Am. Chem. Soc., 1997, 119, 4492-4501.

28 J. Bonvoisin and J.-P. Launay, J. Phys. Chem., 1994, 98, 5052-5057.

29 C. Lambert and G. Nöll, J. Chem. Soc., Perkin Trans. 2, 2002, 2039 2043.

30 K.-W. Poon, W. Liu, P.-K. Chan, Q. Yang, T.-W. D. Chan, T. C. W. Mak and D. K. P. Ng, J. Org. Chem., 2001, 66, 1553-1559.

31 P. D. W. Boyd, A. K. Burrell, W. M. Campbell, P. A. Cocks, K. C. Gordon, G. B. Jameson, D. L. Officer and Z. Zhao, Chem. Commun., 1999, 637-638.

32 K. M. Kadish, Q. Y. Xu and J.-M. Barbe, Inorg. Chem., 1987, 26, 2566-2568.

33 X. Shi, S. R. Amin and L. S. Liebeskind, J. Org. Chem., 2000, 65, 1650-1664.

34 N. Robertson and C. A. McGowan, Chem. Soc. Rev., 2003, 32, 96103.

35 J.-P. Launay, Chem. Soc. Rev., 2001, 30, 386-397.

36 B. Jiang, S.-W. Yang, D. C. Barbini and W. E. Jones Jr., Chem. Commun., 1998, 213-214.

37 C. K. Schauer, O. P. Anderson, S. S. Eaton and G. R. Eaton, Inorg. Chem., 1985, 24, 4082-4086.

38 W. R. Scheidt, M. E. Kastner and K. Hatano, Inorg. Chem., 1978, 17, 706-710.

39 P. N. Taylor, A. P. Wylie, J. Huuskonen and J. L. Anderson, Angew. Chem., Int. Ed., 1998, 37, 986-989.

40 A. N. Sobolev, V. K. Belsky, I. P. Romm, N. Y. Chernikova and E. N. Guryanova, Acta Crystallogr., Sect. C, 1985, 41, 967-971.

41 F. Odobel, S. Suresh, E. Blart, Y. Nicolas, J.-P. Quintard, P. Janvier, J.-Y. L. Questel, B. Illien, D. Rondeau, P. Richomme, T. Häupl, S. Wallin and L. Hammarström, Chem. Eur. J., 2002, 8, 3027-3046.

42 D. E. Richardson and H. Taube, Inorg. Chem., 1981, 20, 1278-1285.

43 H. Imahori, K. Hagiwara, M. Aoki, T. Akiyama, S. Taniguchi, T. Okad, M. Shirakawa and Y. Sakata, J. Am. Chem. Soc., 1996, 118, 11771-11782.

44 M. R. Wasielewski, G. L. Gaines, G. P. Wiederrecht, W. A. Svec and M. P. Niemczyk, J. Am. Chem. Soc., 1993, 115, 10442-10443.

45 A. Giraudeau, L. Ruhlmann, E. Kahef and M. Gross, J. Am. Chem. Soc., 1996, 118, 2969-2979.

46 K. Kamioka, R. A. Cormier, T. W. Lutton and J. S. Connolly, J. Am. Chem. Soc., 1992, 114, 4414-4415.

47 F. D'Souza, M. E. Zandler, P. Tagliatesta, Z. Ou, J. Shao, E. V. Caemelbecke and K. M. Kadish, Inorg. Chem., 1998, 37, 45674572.

48 G. B. Richter-Addo, S. J. Hodge, G.-B. Yi, M. A. Khan, T. Ma, E. Van Caemelbecke, N. Guo and K. M. Kadish, Inorg. Chem., 1996, 35, 6530-6538.

49 P. Tagliatesta, J. Li, M. Autret, E. Van Caemelbecke, A. Villard, F. D'Souza and K. M. Kadish, Inorg. Chem., 1996, 35, 5570-5576.

50 A. Giraudeau, H. J. Callot, J. Jordan, I. Ezhar and M. Gross, J. Am. Chem. Soc., 1979, 101, 3857-3862.

51 R. A. Rao and B. G. Maiya, Polyhedron, 1994, 13, 1863-1873.

52 R. A. Binstead, M. J. Crossley and N. S. Hush, Inorg. Chem., 1991, 30, 1259-1264.

53 Z. Otwinowski and W. Minor, Methods Enzymol., 1997, 276, $307-$ 326.

54 R. H. Blessing, Acta. Crystallogr., Sect. A, 1995, 51, 33-38.

55 G. M. Sheldrick, Acta. Crystallogr., Sect. A, 1990, 46, 467-473.

56 G. M. Sheldrick, SHELXL-97, University of Göttingen, 1997. 